\title{
Hypertension and Risk of Acute Coronary Syndrome (ACS) in Patients with ACS: A Study on 926 patients with ACS
}

\author{
Research Article
}

\section{Mostafa Madmoli $^{*}$, Masoomeh Saeidilandi ${ }^{2}$, Raha Latifinasab ${ }^{2}$, Shekofeh Fatehimoghaddam ${ }^{2}$, Fariba Mobarez ${ }^{2}$, Pouriya Darabiyan ${ }^{2}$}

1. Emergency Medical Technician, Dezful University of Medical Sciences, Dezful, Iran.

2. Student Research Committee, Ahvaz Jundishapur University of Medical Sciences, Ahvaz, Iran.

\begin{abstract}
Introduction: According to the World Health Organization (WHO), 1 billion people have been affected by hypertension (HTN). Since the role of HTN and its effects on patients with ACS is still unclear, the aim of this study was to determine whether HTN is a risk factor for patients with acute coronary syndrome admitted to ShahidZadeh hospital in Behbahan. Materials and Methods: This is a retrospective cross-sectional descriptive study. In this study, 926 cases of patients with acs with or history of the disease who were referred to ShahidZadeh Hospital in Behbahan during 2016-2017 were studied. The required information was collected through a researcher checklist from the records. Data were then entered into SPSS software version 18. Data were analyzed by descriptive statistics and Chi-square and Chi-square test at a significant level of $\mathrm{P}<0.05$. Results: 926 patients with ACS with an average age of $59.15 \pm 15.5$ were included in this study. In this study there was no significant correlation between gender and history of $\operatorname{HTN}(\mathrm{p}=0.17)$. Among the qualitative demographic variables, only the relationship between marital status and history of HTN was significant. There was a significant relationship between history of HTN with history of MI, history of angina, history of smoking and history of family history of cardiovascular problems $(\mathrm{P}<0.05)$. Conclusion: Considering the high prevalence of cardiovascular problems and the relationship between HTN and cardiovascular problems, especially acute coronary syndrome in this study, it is necessary to provide training and prevention to prevent further cardiovascular disease through Educational class, mass media and cyberspace and improve the level of knowledge of these patients and reduce cardiovascular risk factors.
\end{abstract}

Keywords: Acute Cor onary Syndrome, Hypertension, Risk Factor, Cardiovascular Disease.

\section{Introduction}

Cardiovascular disease is the most common cause of death in the world, with about 1.7 billion deaths a year due to cardiovascular disease $(1,2,3,4)$. And the most common cause of death is in both sexes, both male and female, although in the past 20 years, mortality has decreased in men and has increased in women (5). In Iran, 50\% of the annual mortality rate is related to cardiovascular disease (1). It is estimated that around 25 million people will die due to these diseases in 2020 (6). One of the most common cardiovascular diseases is acute coronary syndrome, with more than 250,000 deaths annually reported as a result of the progression of plaque atherosclerosis $(1,7)$.

The word acute coronary syndrome (ACS) refers to any group of clinical signs consistent with acute myocardial ischemia and includes unstable angina (UA), myocardial infarction without ST elevation, and

*Corresponding Author:

Mostafa Madmoli,

Emergency Medical Technician,

Dezful University of Medical Sciences,

Dezful, Iran.

Email id: mostafamadmoli10@gmail.com myocardial infarction with ST elevation. Every year in the United States, it is close to 1.3 million patients are admitted to the NSTEACS diagnosis, while this is for STEACS of 350,000 patients per year (5).

Acute coronary syndrome has several complications due to its debilitating nature (1). These disability complications include reduced production, which is a source of great harm to the community and family of patients (6). Acute coronary syndrome Accompanied with endothelial damage, rupture of atherosclerotic plaque, platelet activation, thrombosis formation, and ultimately vascular occlusion (9). It is recommended to avoid any recurrent erectile dysfunction in patients with acute coronary syndrome (ACS) with anti-platelet plus aspirin and P2Y12 inhibitor for 12 months (10). Risk factors associated with ACS, which are strongly related to inappropriate lifestyle, include HTN, smoking, diabetes, obesity, and physical inactivity associated with lipid disorders (7).

According to the WHO, 1 billion people are affected by HTN and a major risk factor for all types of cardiovascular disease (5). HTN; high blood pressure diagnosed and treated with medication, diet or exercise or systolic blood pressure above $140 \mathrm{mmHg}$ and diastolic blood pressure above $90 \mathrm{mmHg}$ is defined at 
least in two positions (11) Yun Lin et al. (2012) concluded that HTN as a risk factor for epicardial coronary artery disease may interfere with capillary circulation, which undoubtedly affects women (8). Paul Erne et al., In 2014, concluded that short-term and longterm management of acute coronary syndrome patients with HTN could be improved (12). The role of HTN and its effects on patients with ACS is still not fully understood (13-13). Therefore, this study was conducted to determine the importance of HTN as a risk factor for acute coronary syndrome.

\section{Materials and methods}

The present study is a retrospective cross-sectional study that all patients with ACS referred to ShahidZadeh hospital in Behbahan city who were diagnosed with ACS or history of ACS in their case during 2016-2017. After obtaining the necessary permissions and financial support from Behbahan Faculty of Medical Sciences, the files were used for this study.

In this study, 926 cases of patients who had ACS or a history of this condition were studied.

The required data for the study were extracted from patients' archives during 2016-2017 by reviewing and retrieving patient's files. The criteria for entering the study included all ACS in each age group and sex with any diagnosis or history of ACS in their case, and other records that had a medical diagnosis other than the disease, cases without ACS history, and cases Incomplete $(\mathrm{n}=75)$ were excluded.

In order to study the files and collect data, a written Letter of Introduction from the Faculty of Medical Sciences of Behbahan to the ShahidZadeh Hospital of Behbahan was received by the ViceChancellor of Education and Research at the ShahidZadeh Hospital in order to access the archives.
After obtaining permission from the chairman of ShahidZadeh Hospital, 926 cases were investigated. The required information was collected through a researcher checklist from the records.

Data included in this study including demographic, laboratory and clinical data such as gender, age, marital status, ethnicity, occupation, economic status, educational level, history of smoking, history of angina, history of cardiovascular disease in the family, and history HTN was studied. Data were then entered into SPSS software version 18. Data were analyzed by descriptive statistics and Chi-square and Chi-square test at a significant level of $\mathrm{P}<0.05$.

\section{Results}

In this study, 926 patients with a mean age of $17.15 \pm 59.00$ were ACS. Of these, $56.6 \%$ were male and the rest were female. In terms of jobs, the highest number of people, $42.6 \%$ were unemployed. In terms of marital status, the highest percentage was married (60.6\%). In this study, 402 (43.4\%) males and 524 $(56.6 \%)$ were female, and there was no significant correlation between gender and history of HTN ( $p=$ $0.17)$.

Among the different ethnic groups, the largest number of people were lor tribes, with 516 (55.7\%), Shoushtari-Dezfuli 205 (22.1\%), Arabs with 201 $(21.7 \%)$ and Kurds with $4(0.4 \%)$. The relationship between ethnicity and history of HTN was not significant $(\mathrm{p}=0.63)$. Table 1 shows the demographic data of these patients and their association with the history of HTN.

Among the qualitative demographic variables, only the relationship between marital status and history of HTN was significant ( $\mathrm{p}<0.0001)$. Figure 1 .

Table 1. Demographic Characteristics of ACS Patients and Its Relation to Blood Pressure by Chi-square and Chi-square Pearson Test

\begin{tabular}{|c|c|c|c|c|}
\hline Variable & Classification & Number & Percentage & $\begin{array}{c}\text { Association with HTN } \\
\text { P value }\end{array}$ \\
\hline \multirow[t]{5}{*}{ Education } & Illiterate & 420 & 45.4 & \multirow[t]{5}{*}{0.45} \\
\hline & Elementary & 260 & 28.1 & \\
\hline & Third grade middle school & 81 & 8.7 & \\
\hline & Diploma & 129 & 13.9 & \\
\hline & Bachelor's degree and higher & 36 & 3.9 & \\
\hline \multirow[t]{4}{*}{ Occupation } & Unemployed & 400 & 42.6 & \multirow[t]{4}{*}{0.19} \\
\hline & Free & 185 & 19.6 & \\
\hline & Employee & 61 & 6.7 & \\
\hline & Housewife & 280 & 31.1 & \\
\hline \multirow{3}{*}{$\begin{array}{l}\text { The economic situation } \\
\text { (Monthly Tomans) }\end{array}$} & Up to 500 thousand & 348 & 37.6 & \multirow[t]{3}{*}{0.18} \\
\hline & 500 to 1 million & 421 & 45.5 & \\
\hline & 1 million and above & 157 & 17.0 & \\
\hline
\end{tabular}


Figure 1: Distribution of marital status of patients with ACS in patients with and without a history of HTN

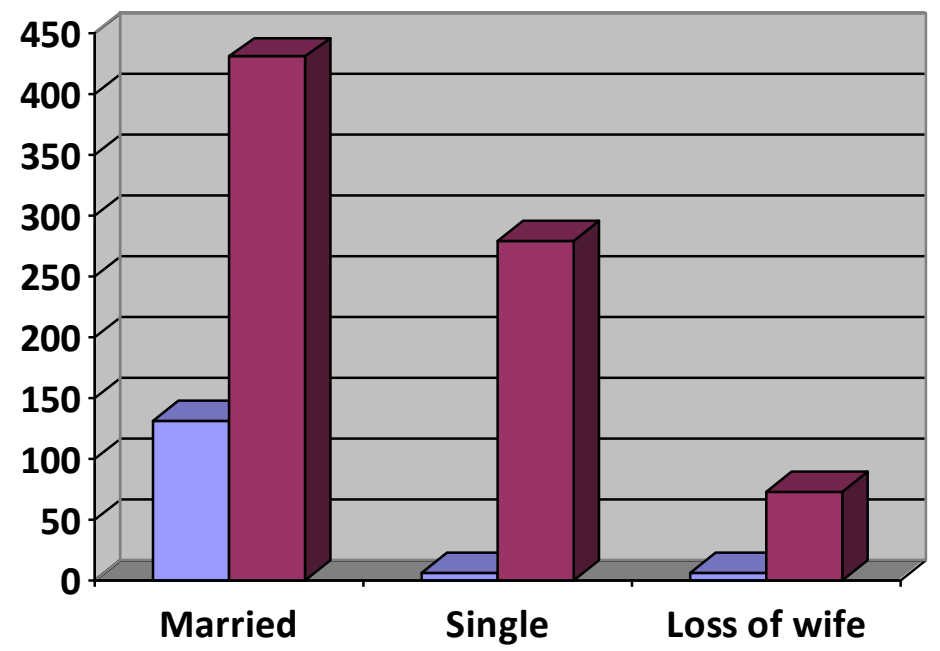

$\square$ Had history of HTN

No history of HTN

In this study 15.6 patients had a history of HTN and the rest did not have it. (92.9\%) had no history of angina. Also, (11.6) percent had a history of MI and the rest had no history. In terms of history of family history of heart disease $(7.1 \%)$, they had a history of the disease and the rest of the population had no history.

There was a significant relationship between the history of HTN with the history of MI, history of angina, history of smoking and family history of cardiovascular problems $(\mathrm{P}<0.05)$ (Table 2$)$.

Table 2. Frequency and frequency percent of history of HTN and its relationship with history of angina, history of smoking and history of family history of cardiovascular problems in patients with ACS

\begin{tabular}{|c|c|c|c|c|c|c|}
\hline Variable & Frequency & $\begin{array}{c}\text { Frequency } \\
\text { percent }\end{array}$ & $\begin{array}{l}\text { Relationship } \\
\text { with a history } \\
\text { of smoking }\end{array}$ & $\begin{array}{c}\text { Relationship } \\
\text { with the } \\
\text { history of } \mathrm{MI}\end{array}$ & $\begin{array}{c}\text { Relationship } \\
\text { with the his- } \\
\text { tory of Angi- } \\
\text { na }\end{array}$ & $\begin{array}{c}\text { Relationship } \\
\text { with the } \\
\text { history of } \\
\text { family history } \\
\text { of heart } \\
\text { disease } \\
\end{array}$ \\
\hline \multirow{2}{*}{$\begin{array}{c}\text { History of } \\
\text { HTN }\end{array}$} & 144 Yes & 15.6 & \multirow[t]{2}{*}{$<0.0001$} & \multirow[t]{2}{*}{0.001} & \multirow[t]{2}{*}{$<0.0001$} & 0.006 \\
\hline & $\begin{array}{ll}782 & \text { No }\end{array}$ & 84.4 & & & & \\
\hline
\end{tabular}

* A significant level below 0.05 is considered.

\section{Discussion}

Cardiovascular disease is the most common cause of death in the world and is the leading cause of death in both sexes. Although in the past 20 years' deaths from these diseases have decreased in men and increased in women. In Iran, $50 \%$ of the causes of death are related to cardiovascular diseases each year. According to the WHO, HTN affects 1 billion people and is a major risk factor for all types of cardiovascular disease $(1,5)$. The aim of this study was to determine whether HTN is a risk factor for patients with acute coronary syndrome admitted to ShahidZadeh hospital in Behbahan.

In this study 15.6 patients had a history of HTN and the rest did not have it. Among the qualitative demographic variables, only the relationship between marital status and history of blood pressure was significant. There was a significant correlation between ex-blood pressure with all of the history of MI, history of angina, history of smoking, and family history of heart disease. The results of a study conducted by Khot
$\mathrm{UN}$ and colleagues showed that $6.84 \%$ of women and $6.80 \%$ of men had at least one of the four major cardiovascular risk factors (HTN, diabetes, cigarette and dyslipidemia) (14). The study (15) showed that there was no significant difference in total cholesterol and LDL-C in the comparison of the two groups of patients with coronary disease (386 patients) without coronary disease (181 persons), but there was no significant difference in the incidence of triglyceride and HDL-C You were there. In study (16), the prevalence of major risk factors for atherosclerosis was very high and only $5.9 \%$ of patients with acute coronary syndrome did not have any major risk factors for atherosclerosis.

In a study on patients with acute coronary syndrome, $30 \%$ of diabetic patients, $42 \%$ smokers and $91 \%$ had high blood pressure. 25\% had MI and 76\% had unstable angina. Also, MI was significant in diabetic patients and the location and expansion of MI enzymes and cardiac enzymes did not differ between diabetic and non-diabetic patients. High blood pressure 
and smoking in patients with MI were significantly higher than patients with unstable angina (17). Diabetes, the most common metabolic disease and a risk factor for heart disease (22-18), increases the risk of heart disease several times, so that in the study of Madmoli et al. The prevalence of heart problems in patients The diabetic was $39.7 \%$ (23).

In this study, the number of men with heart problems was higher than that of women (24). But in the study by Madmoli et al. (23), Rovan VU (25) and Stoekenbroek RM (26) had more women than men, which may be due to differences in the sample size, different styles of their lives, the situation Different nutrition or their sexual characteristics. The study (23) also showed that people with lower literacy were significantly more likely to have type 2 diabetes than those with a more educated age, which more likely to develop diabetes could increase its complications, such as cardiac complications, Therefore, there is a need for prevention in this area.

In a study (27) on type 2 diabetic patients, $26.8 \%$ of patients had coronary artery disease (CHD), of which $47 \%$ had no knowledge of their disease and they were found to have a history of coronary artery disease.

In the study (28) in Isfahan, coronary artery disease in diabetics was $28 \%$. Finally, it can be said that among the chronic diseases, cardiovascular disorders have been accepted as the main cause of death by the scientific community. Unlike most diseases, HTN is not a sign and externality, and it may be years without a person's knowledge, High blood pressure, so they have called the disease (the killer of loneliness) (29), so that prevention is necessary in this regard.

\section{Conclusion}

Considering the high prevalence of cardiovascular problems and the fact that there was a significant relationship between history of HTN with history of MI, history of angina, smoking history and history of family history of heart disease, It is necessary to provide training and prevention to prevent further cardiovascular disease through the educational class, mass media and cyberspace in order to raise the level of education of these patients and reduce cardiovascular risk factors. Also, because prevention is always prioritized, it is therefore recommended that training should be provided to patients with acute coronary syndrome in the field of treatment, prevention and other necessary training through treatment staff, especially nurses, because of the direct and continuous relationship with patients, be provided.

\section{Acknowledgment}

The authors of this article appreciate the staff of Shahidzadeh Hospital, deputy and staff of Behbahan Faculty of Medical Sciences, and all those who cooperated with us.

\section{Conflict of interest}

There are no conflicts of interest in this study.

\section{References}

1. Relation between health promotion behaviors life style and Islamic life style in Patients with acute coronary syndrome. Journal of Clinical Nursing and Midwifery. 2018;7(2):126-37.

2. Adavi A, Fathi Marghmalaki R, Madmoli Y, Fathi Marghmalaki R, Madmoli M. The Effect of Stress Management on Anxiety of Females with Hypertension. IJNR. 2016; 11 (5) :7-12

3. Adavi A, Marghmalaki F, Madmoli Y, Madmoli M. Investigate the effectiveness of cognitive-behavioral stress management intervention on aggression in women with hypertension. Journal of Clinical Nursing and Midwifery. 2017;4(3).

4. Madmoli M, Eilami O, Rezaie K, Aliabad MA, Moslemirad M. DIABETES AND THE RISK OF SUFFERING CARDIOVASCULAR DISEASES: A TWO-YEAR RETROSPECTIVE STUDY.

5. Lin $Y$, Pan $W$, Ning $S$, Song $X$, Jin $Z$, Lv $S$. Prevalence and management of hypertension in patients with acute coronary syndrome vary with gender: Observations from the Chinese registry of acute coronary events (CRACE). Mol Med Rep. 2013;8(1):173-7.

6. Majidi SA, Moghadam nia MT, Sharifi $M$. Comparison of Signs and Symptoms Associated with Acute Coronary Syndrome in Male and Female Patients. Journal of Guilan University of Medical Sciences. 2012;20(80):60-6.

7. Vafaeimanesh J, Hejazi F, Vahedian M, Tabaraii R, Bagherzadeh M, Khalesi AA. Evaluation of Risk Factors for Acute Coronary Syndrome in Patients Referring to the Cardiology Clinic of Shahid Beheshti Hospital in Qom City, 2015, Iran. Qom Univ Med Sci J. 2017;10(10):50-60.

8. Zandparsa A F, Jafari H, Tabatabai Gh. Low molecular weight heparin versus Unfractionated heparin in patients with non ST-elevation acute coronary syndrome: a randomaized clinical trial. Tehran University Medical Journal. 2007;65(6):238.

9. Barzegari H, Maleki verki M, Seyedian S, Ghani Kakhaki M. Platelet Count in Patients with Acute Coronary Syndrome. Iranian Journal of Emergency Medicine.5(1).

10. Vyas A, Bash LD, Patel MD, Simpson RJ, Jr. Changes in Treatment Patterns and Incremental Health Care Utilization Due to P2Y12-Associated Complications in Patients with Acute Coronary Syndrome. Journal of managed care \& specialty pharmacy. 2017;23(9):947-56.

11. Ali WM, Zubaid M, El-Menyar A, Al Mahmeed W, Al-Lawati J, Singh R, et al. The prevalence and outcome of hypertension in patients with acute 
coronary syndrome in six Middle-Eastern countries. Blood pressure. 2011;20(1):20-6.

12. Erne P, Radovanovic D, Schoenenberger AW, Bertel O, Kaeslin T, Essig M, et al. Impact of hypertension on the outcome of patients admitted with acute coronary syndrome. Journal of hypertension. 2015;33(4):860-7.

13. Lindschou Hansen J, Tolstrup JS, Jensen MK, Gronbaek M, Tjonneland A, Schmidt EB, et al. Alcohol intake and risk of acute coronary syndrome and mortality in men and women with and without hypertension. European journal of epidemiology. 2011;26(6):439-47.

14. Khot UN, Khot MB, Bajzer CT, Sapp SK, Ohman EM, Brener SJ, Ellis SG, Lincoff AM, Topol EJ.

Prevalence of conventional risk factors in patients with coronary heart disease. JAMA. 2003; 290:898904.

15. Haidari M, Moghadam M, Chinicar M, Ahmadieh A, Doosti M. Apolipoprotein B as the best predictor of coronary artery disease in Iranian normolipidemic patients. Clin Biochem. 2001;34: 149-155.

16. Birannard M r, Asadpuorpieranfar M. Dyslipidemia in acute coronary syndrome.2006. 377-384.

17. Esteghamati A, Abbasi M, Nakhjavani M, Yousefizadeh A, Basa AP, Afshar H. Prevalence of diabetes and other cardiovascular risk factors in an Iranian population with acute coronary syndrome. Cardiovascular Diabetology. 2006 Dec;5(1):15.

18. Moslemirad M, Madmoli M, Madmoli Y, Niksefat M. Prevalence of type 1 and type 2 diabetes and its related factors in diabetic patients hospitalized in Khatam-ol-Anbia hospital in Shoushtar, 2014-15: A retrospective study. Journal of Research in Medical and Dental Science. 2018;6(3):421-6.

19. Madmoli M Rostami F, Mirsami Yazdi N, Mosavi A, Baraz Sh. Evaluation of Prevalence of Diabetic Foot Ulcer and Its Related Factors in Diabetic Patients Admitted to KHatam-ol-Anbia Hospital in Shoushtar During 2015-2016: A Retrospective Study. International Journal of Ecosystems and Ecology Science (IJEES). 2018 June; 8 (3): 545-52.

20. Rostami F, Madmoli M, Mirsami Yazdi N, Baraz Sh. Evaluation of The Prevalence of Lower Limb Amputation and Its Related Factors in Diabetic Patients Admitted to KHatam-ol-Anbia Hospital in Shoushtar During The 2015-2016: A Retrospective Study. International Journal of Ecosystems and Ecology Science (IJEES). 2018 June; 8 (3): 553-60.
21. Raisifar Z, Afshar Nia A, Madmoli M, Madmoli Y. The Relationship Between Using Insulin and Suffering Alzheimer's Disease in Patients with Diabetes: A Two-Year Study. International Journal of Ecosystems and Ecology Science (IJEES). 2018 June; 8 (3): 623-28.

22. Raisifar Z, Afshar Nia A, Maghamesi Moarrefi H, Madmoli M. Evaluation of Gi Bleeding Prevalence and Its Related Factors in Diabetic Patients Hospitalized in KHatam-ol-Anbia Hospital During 2015-16: A Retrospective Study. International Journal of Ecosystems and Ecology Science (IJEES). 2018 June; 8 (3): 609-14.

23. Madmoli M, Eilami O, Rezaie K, Aliabad MA, Moslemirad M. Diabetes and the risk of suffering cardiovascular Diseases: A two-year retrospective study. International Journal of Ecosystems and Ecology Science (IJEES). 2018 Jun;8(3): 649-56.

24. Frykberg RG, Gibbons GW, Walters JL, Wukich DK, Milstein FC. A prospective, multicentere, openlabel, single-arm clinical trial for treatment of chronic complex diabetic foot wounds with exposed tendon and/or bone: positive clinical outcomes of viable cryopreserved human placental membrane. Int wound j. 2016; 14: 569-577. doi: 10.1111/ iwj. 12649.

25. Rovan VU, Rovan J. An exploration of diabetic foot screening procedures data by a multiple correspondence analysis. Slovenian Journal of Public Health. 2017 Mar 1;56(1):65-73.

26. Stoekenbroek RM, Lokin JLC, Nielen MM, Stroes ESG. How common are foot problems among individuals with diabetes? Diabetic foot ulcers in the Dutch population. Diabetologia. 2017; 60: 12711275. doi: 10.1007/s00125-017-4274-7.

27. Kashi Z, Bahar A, Akha O, Sharif F, Kosaryan M, Jalalian R, Aarabi M. Ischemic Heart Disease and Related Factors in Patients with Diabetes Mellitus Type II. Journal of Mazandaran University of Medical Sciences. 2015 Oct 15;25(129):9-16.

28. Janghorbani M, Amini M, Tavassoli A. Coronary heart disease in type 2 diabetes mellitus in Isfahan, Iran: prevalence and risk factors. Acta Cardiol 2006; 61(1): 13-20.

29. Adavi A, Fathi Marghmalaki R, Madmoli Y, Fathi Marghmalaki R, Madmoli M. The Effect of Stress Management on Anxiety of Females with Hypertension. Iranian Journal of Nursing Research.2016;11(5): 7-12. 